\title{
Failure Behavior and Damage Characteristics of Coal at Different Depths under Triaxial Unloading Based on Acoustic Emission
}

\author{
Anlin Zhang ${ }^{1,2}$, Ru Zhang ${ }^{1,3, *}$, , Mingzhong Gao ${ }^{1,3,4}$, Zetian Zhang ${ }^{1,2, *}$, Zheqiang Jia ${ }^{1,2}$, \\ Zhaopeng Zhang ${ }^{3}$ and Ersheng Zha ${ }^{1,2}$ \\ 1 College of Water Resource \& Hydropower, Sichuan University, Chengdu 610065, China; \\ zhanganlin@stu.scu.edu.cn (A.Z.); gmzh@scu.edu.cn (M.G.); jiazheqiang0921@icloud.com (Z.J.); \\ zhaersheng@stu.scu.edu.cn (E.Z.) \\ 2 State Key Laboratory of Hydraulics \& Mountain River Engineering, Sichuan University, \\ Chengdu 610065, China \\ 3 MOE Key Laboratory of Deep Earth Science \& Engineering, Sichuan University, Chengdu 610065, China; \\ zhangzp@scu.edu.cn \\ 4 Institute of Deep Earth Science \& Green Energy, Shenzhen University, Shenzhen 518060, China \\ * Correspondence: zhangru@scu.edu.cn (R.Z.); zhangzetian@scu.edu.cn (Z.Z.); Tel.: +86-138-8000-9601 (R.Z.); \\ +86-139-8076-7462 (Z.Z.)
}

Received: 28 June 2020; Accepted: 25 August 2020; Published: 28 August 2020

\begin{abstract}
The depth effect of coal mechanical behavior seriously affects the safety and efficiency of deep coal mining. To explore the differences in failure behavior and damage characteristics of coal masses at different depths during the coal mining process, based on the consideration of in situ stress environment, physical properties, and mining disturbance of coal seams, triaxial unloading experiments with acoustic emission (AE) monitoring were conducted on coal samples at four different depths taken from the Pingdingshan coal mine area. The results showed that the AE activity of deep coal was more concentrated, and the cumulative AE energy of coal increased with increasing depth. The cumulative AE energy of the 1050-m coal sample was 69 times that of the $300-\mathrm{m}$ coal sample. The $b$ value representing the microcrack scale decreased with increasing depth, and the rupture degree of deep coal increased. The cracking mode of coal was classified and the failure behavior was analyzed. The cumulative tensile crack percentage of coal increased with increasing depth, and the tensile-shear composite failure occurred in the $300-\mathrm{m}$ coal sample, whereas significant tensile failure occurred in the 1050-m coal sample. In addition, the damage evolution process of coal was divided into three stages, and the characteristic stress of coal was obtained. The ratio of crack initiation stress $\left(\sigma_{\mathrm{ci}}\right)$ to peak stress $\left(\sigma_{\mathrm{c}}\right)$ increased with increasing depth, and the damage evolution process of deep coal was more rapid. The research results can provide useful guidance for disaster prevention and evaluation of surrounding rock stability during deep coal resource mining in the Pingdingshan coal mine area.
\end{abstract}

Keywords: coal; different depths; mining disturbance; acoustic emission (AE); crack classification; failure behavior; damage

\section{Introduction}

With the rapid development of human society, shallow resources are gradually being exhausted, and the exploitation of deep resources is becoming a normal occurrence. Coal resources are still the main source of energy in China. However, as coal mining gradually enters deeper areas, coal and gas outbursts, high-energy rock bursts and mine shocks, large-scale roof-fall accidents, and other mine 
disasters occur frequently, but the mechanism driving these phenomena is unclear [1]. Attempts to effectively predict and control these disasters and accidents is impeded by substantial challenges. The main reason is that deep rock mechanics research lags far behind deep engineering practice, and the comprehensive influence of the depth, in situ stress environment, and engineering disturbances on deep coal mining activities is not fully recognized [2]. It is of great guiding significance for the safe and efficient mining of deep coal resources to systematically study the mechanical behavior of coal considering the effects from the depth effect, in situ stress environment, and mining disturbances.

Tensile failure and shear failure are common forms of coal instability failure and the root cause of mine disasters [3]. The cause and mechanism of deep mining disasters can be elucidated by studying the tensile and shear failure behavior of coal [4]. To date, the research on coal failure behaviors or modes focused on the phenomenological description of the experimental results of failure mechanics such as uniaxial compression, tension, and triaxial compression [5-8], and there were also very few scholars who used acoustic emission (AE) technology to analyze the mechanical mechanism driving the destructive behavior of coal. For example, Zhang et al. [9] investigated the failure mechanism of coal pillars under uniaxial compression by analyzing the evolution of the AE energy release. Liu et al. [10] studied the difference in the failure behavior of dry coal and water-containing coal under true triaxial stress conditions through a combination of AE characteristic parameters. Yao et al. [11] studied the differences in crack propagation and failure modes of coal samples with different water contents under uniaxial compression. These results deepened our understanding of coal failure behavior, but there are still some deficiencies in the existing research. On the one hand, experimental simulations fail to replicate the actual mining conditions of coal; on the other hand, there is a lack of in-depth mechanical mechanism analysis and spatial-temporal location determination of coal failure behavior at different depths. Therefore, it is still necessary to conduct further research on the failure behavior, damage, and deformation of coal at different depths based on simulating the actual coal mining process.

The rock failure process is essentially a dynamic evolution process of microcrack initiation and propagation. Moreover, part of the stored energy is released instantaneously in the form of a stress wave, resulting in the rock $\mathrm{AE}$ phenomenon [12]. With the help of AE monitoring technology, nondestructive, real-time monitoring of microcrack evolution, damage, and deformation in rocks under loaded conditions can be achieved. AE monitoring technology is gradually becoming an effective tool for studying rock destructive behavior $[13,14]$. Some scholars studied the mechanical properties and deformation damage of coal through AE experiments. Shan et al. [15] used an AE test to study the energy dissipation and liberation of coal fracture under complex excavation conditions. Xue et al. [16] studied the effect of the stress path on mechanical behavior of coal by evaluating the AE characteristics under different mining conditions. Yang et al. [17] performed AE experiments on coal samples with different properties and under different stress conditions, and they explored the evolution mode of $\mathrm{AE}$ activity and the type of coal destruction. Based on the processing and analysis of the characteristic parameters of AE signals, Shkuratnik et al. [18] divided the deformation and failure stages of coal samples under uniaxial compression, Jia et al. [19] revealed the differences in damage evolution of coal samples at different depths under triaxial compression, Zhang et al. [20] explored the differences in the deformation and failure of coal samples in different bedding directions under uniaxial compression, Su et al. [21] systematically studied the failure process of coal samples under different stress paths, and Liu et al. [22] introduced a damage variable based on AE parameters to study the damage evolution characteristics of coal. It can be seen that the AE signals from a coal sample adequately reflect the deformation and damage evolution characteristics of coal. However, direct analysis of the characteristic parameters of the AE signals cannot classify distinct rock failure behavior. Therefore, based on moment tensor analysis, Ohtsu et al. [23] studied the combined form of AE characteristic parameters and found that the $A F$ value (AE counts/duration) and $R A$ value (rise time/amplitude) can be effectively used to determine the mode of internal cracks in materials. Later, this method was included in the Japanese building code [24]. On the basis of Ohtsu's research, Li et al. [25] identified the crack modes of ice structures in alpine regions and revealed the differences in the fracture modes of ice structures 
under different loading conditions. Ohno et al. [26] classified cracks in concrete and discussed the transformation mechanism of tensile and shear behavior when the concrete was in a state of critical instability. Wang et al. [27] determined the crack modes of anisotropic shale under cyclic loading and revealed the difference in the failure behavior of shale at different bedding angles. According to the distribution of $\mathrm{AE}$ parameter combinations $(R A$ and $A F)$ in a rock burst experiment of granite with defined core density, He et al. [28] analyzed the evolution process of tensile and shear cracks in granite. Zhou et al. [29] classified the cracking modes of marble under stepwise cyclic loading via the correlation analysis of the $A F-R A$ value, and they studied the influence of initial cycle amplitude on the failure patterns of marble. Niu et al. [30] used $A F-R A$ correlation analysis to evaluate the cracking modes during the uniaxial compression progress of defective red sandstone, and the results obtained were consistent with the macroscopic crack types captured by digital image correlation (DIC) technology. In summary, rock $\mathrm{AE}$ was widely used in rock mechanics researches, and scholars also widely used the correlation analysis of $\mathrm{AE}$ combined parameters $(A F$ and $R A)$ to study the cracking modes and failure behaviors of rocks or rock-like materials. However, the associated studies of AE characteristics of coal at different depths are rarely reported, especially using the correlation analysis of $R A-A F$ to study the differences in cracking modes and failure behaviors of coal under mining unloading conditions.

The depth effect of coal mechanical behavior under mining conditions seriously affects the safety and efficiency of deep coal mining. The mining-induced failure behavior and damage deformation of coal are the key influencing factors of disasters and accidents in deep coal mining. However, there is still a lack of mechanical mechanism research on the differences in unloading failure behavior and damage characteristics of coal at different depths under actual mining conditions. Therefore, in this paper, with the help of AE monitoring technology, coal samples at four depths $(300 \mathrm{~m}, 600 \mathrm{~m}, 850 \mathrm{~m}$, and $1050 \mathrm{~m}$ ) in the Ji group coal seam of the Pingdingshan coal mine area were taken as experimental objects. Considering the influence of the physical coal properties, in situ stress environment, and mining disturbances, an experimental simulation (triaxial unloading experiment) and AE signal synchronous monitoring of the coal mining unloading process at different depths were carried out. The AE characteristic parameters were analyzed to reveal the spatial-temporal evolution characteristics of $\mathrm{AE}$ and the difference in energy catastrophes during triaxial unloading of coal samples at different depths. Based on the combination of AE characteristic parameters, the crack modes in coal samples at different depths were classified. The differences in the spatial-temporal evolution law of tensile and shear cracks, mechanical failure behavior, and damage evolution characteristics in the process of the triaxial unloading experiments of the coal samples at different depths were systematically explored to reveal the influence of depth on the failure behavior, damage, and deformation of coal and rock masses during coal mining operations. The research results have important scientific guiding significance for the efficient and safe mining of deep coal resources in the Pingdingshan coal mining area, and they can also provide a useful reference for other deep coal mining engineering practices.

\section{Experimental Procedures}

\subsection{Sample Preparation}

The coal samples used in the experiment were taken from the Ji group coal seam in the Pingdingshan coal mine area, with burial depths of $300 \mathrm{~m}, 600 \mathrm{~m}, 850 \mathrm{~m}$, and $1050 \mathrm{~m}$. The four deep coal samples obtained were generated in the same geological period to ensure that the experimental coal samples met the requirements of consistent lithology and different depths as much as possible. Furthermore, in accordance with the recommendations of the International Society for Rock Mechanics (ISRM), the coal samples from different depths were processed into standard cylindrical specimens with dimensions of $\Phi 50 \mathrm{~mm} \times H 100 \mathrm{~mm}$. The typical coal samples prepared at four depths are shown in Figure 1. 


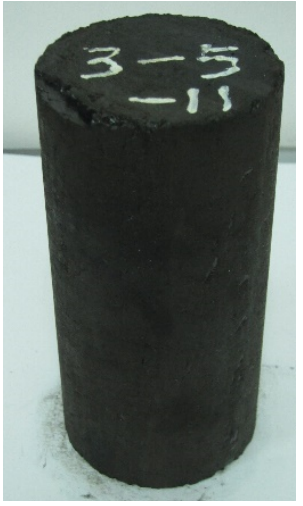

(a)

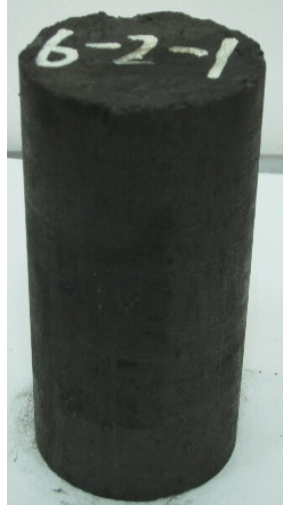

(b)

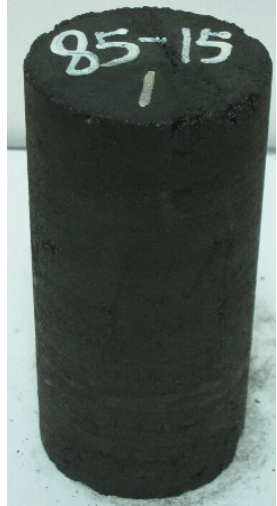

(c)

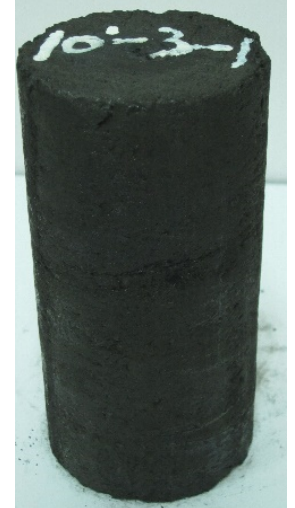

(d)

Figure 1. Typical coal samples prepared at different depths: (a) $300 \mathrm{~m}$, (b) $600 \mathrm{~m}$, (c) $850 \mathrm{~m}$, and (d) $1050 \mathrm{~m}$.

\subsection{Test Equipment}

An MTS 815 rock mechanics test system and the AE system at Sichuan University were used as experimental equipment, as shown in Figure 2. The MTS 815 rock mechanics test system is a fully digital computer-controlled system. The axial load is $0-4600 \mathrm{kN}$, the axial displacement is $\pm 50 \mathrm{~mm}$, and the ranges of the axial and circumferential deformation extensometers are -4.0 to $4.0 \mathrm{~mm}$ and -2.5 to $12.5 \mathrm{~mm}$, respectively. This set-up can record the load, stress, and displacement in real time and draw the load-displacement curve synchronously.

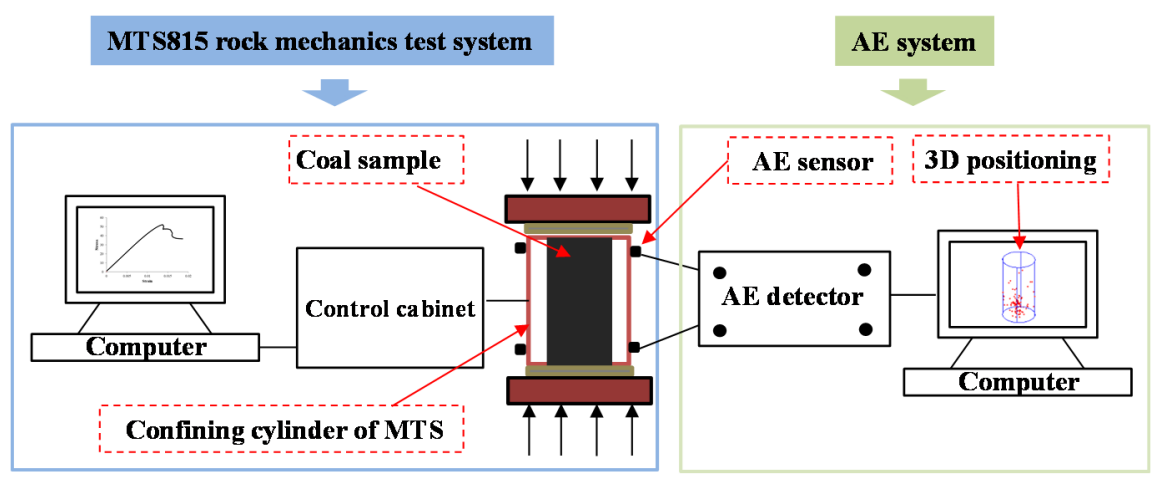

Figure 2. Schematic diagram of MTS815 rock mechanics test system and acoustic emission (AE) system.

The AE system used in the test has an 18-bit analog to digital (A/D) architecture, including a bandwidth frequency range of $1 \mathrm{kHz}-3 \mathrm{MHz}$, a maximum signal amplitude of $100 \mathrm{~dB}$, and a dynamic range of greater than $85 \mathrm{~dB}$. AE events during the process of rock deformation and failure are automatically counted, stored, and positioned in space. During the experiment, eight AE sensors were evenly placed on the outer wall of the MTS triaxial confining cylinder, and Vaseline was applied at the contact area to ensure the coupling effect. The vertical distance between the upper and lower distribution points of the sensor and the two faces of the coal sample was approximately $10 \mathrm{~mm}$, and the $\mathrm{AE}$ threshold was set to $40 \mathrm{~dB}$.

\subsection{Testing Program}

Based on the on-site measured and collected statistical results of the initial in situ stress in the coal seam at different depths in the Pingdingshan coal mine area, the simulation method of $\sigma_{3}=\sigma_{\mathrm{H}}$ (confining pressure $=$ maximum measured in situ stress) was adopted for the initial stress environment of coal samples at different depths [31]. According to this, the initial confining pressures of the coal samples at burial depths of $300 \mathrm{~m}, 600 \mathrm{~m}, 850 \mathrm{~m}$, and $1050 \mathrm{~m}$ in the Pingdingshan coal mine area were 
14.2 $\mathrm{MPa}, 31.3 \mathrm{MPa}, 40.7 \mathrm{MPa}$, and 43.6 MPa, respectively. Referring to the generalization method of the mining stress path by Xie et al. [32,33], the experimental process was divided into three stages: the hydrostatic pressure stage, the first unloading stage, and the second unloading stage (as shown in Figure 3).

(1) Hydrostatic pressure stage: The confining pressure was applied to $\sigma_{2}=\sigma_{3}=\sigma_{\mathrm{H}}$ at a loading rate of $3 \mathrm{MPa} / \mathrm{min}$, and the initial confining pressures of the coal samples at depths of $300 \mathrm{~m}, 600 \mathrm{~m}$, $850 \mathrm{~m}$, and $1050 \mathrm{~m}$ were $14.2 \mathrm{MPa}, 31.3 \mathrm{MPa}, 40.7 \mathrm{MPa}$, and $43.6 \mathrm{MPa}$, respectively, as shown in section OA in Figure 3.

(2) First unloading stage: Considering the impact of the initial mining disturbance, the stress state of the coal samples at different mining depths gradually changed from the hydrostatic confining pressure state to $\sigma_{1}=1.5 \sigma_{\mathrm{H}}$ and $\sigma_{3}=0.6 \sigma_{\mathrm{H}}$. Hence, the ratio of the increase in axial deviatoric stress $\left(\sigma_{1}-\sigma_{3}\right)$ and the decrease in confining pressure $\left(\sigma_{3}\right)$ of the coal sample was 2.25:1, as shown in section $\mathrm{AB}$ in Figure 3. The rate of the unloading confining pressure in the test was set to $1 \mathrm{MPa} / \mathrm{min}$.

(3) Second unloading stage: Considering the increase in mining disturbance, it was assumed that, as the mining depth increases, the confining pressure of the coal near the mining face is linearly distributed. A stress path diagram shows the progress of keeping the rate of unloading confining pressure at $1 \mathrm{MPa} / \mathrm{min}$, increasing the rate of roof pressure (axial stress) and controlling the ratio of the increase in axial deviatoric stress $\left(\sigma_{1}-\sigma_{3}\right)$ and the decrease in confining pressure $\left(\sigma_{3}\right)$ to $4.75: 1$, as shown in section BC in Figure 3. Accordingly, the evolution path of mining disturbance unloading stress experienced by coal near the working face was simulated, and the testing program of coal samples at different depths is shown in Table 1.

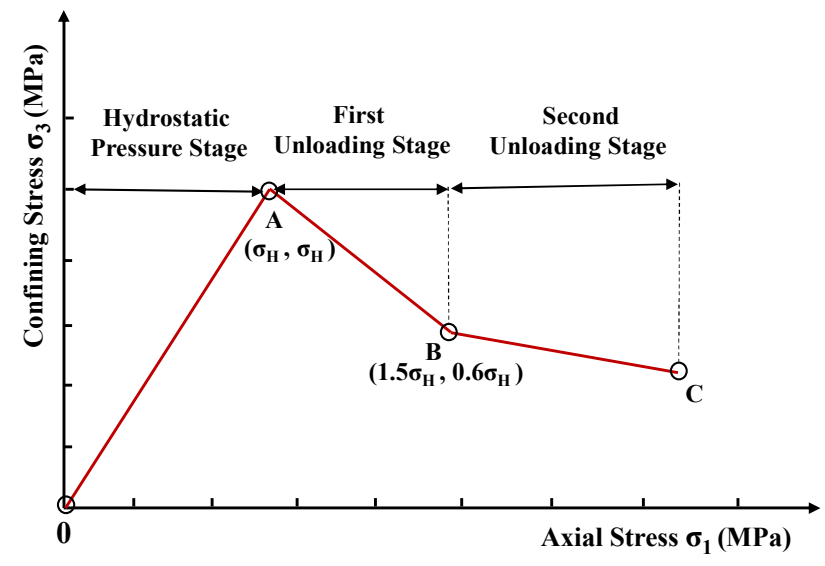

Figure 3. Stress path diagram for the triaxial unloading experiment $[32,33]$.

Table 1. Triaxial unloading testing program of coal samples at different depths.

\begin{tabular}{|c|c|c|c|c|c|c|}
\hline $\begin{array}{l}\text { Depth } \\
\text { (m) }\end{array}$ & $\begin{array}{c}\text { Loading Rate of } \\
\sigma_{3} \text { in OA } \\
\left(\mathrm{MPa} \cdot \mathrm{min}^{-1}\right)\end{array}$ & $\mathrm{A}\left(\sigma_{\mathrm{H}}, \sigma_{\mathrm{H}}\right)(\mathrm{MPa})$ & $\begin{array}{c}\text { Loading Rate of } \\
\sigma_{1}-\sigma_{3} \text { in } \mathrm{AB} \\
\left(\mathrm{MPa} \cdot \mathrm{min}^{-1}\right)\end{array}$ & $\begin{array}{c}\mathrm{B}\left(1.5 \sigma_{\mathrm{H}}, 0.6 \sigma_{\mathrm{H}}\right) \\
(\mathrm{MPa})\end{array}$ & $\begin{array}{c}\text { Loading Rate of } \\
\sigma_{1}-\sigma_{3} \text { in BC } \\
\left(\mathrm{MPa} \cdot \mathrm{min}^{-1}\right)\end{array}$ & $\begin{array}{c}\text { Unloading Rate } \\
\text { of } \sigma_{3} \text { in AC } \\
\left(\mathrm{MPa} \cdot \mathrm{min}^{-1}\right)\end{array}$ \\
\hline 300 & 3.00 & $(14.20,14.20)$ & 2.25 & $(21.30,8.52)$ & 4.75 & 1.00 \\
\hline 600 & 3.00 & $(31.30,31.30)$ & 2.25 & $(46.95,18.78)$ & 4.75 & 1.00 \\
\hline 850 & 3.00 & $(40.70,40.70)$ & 2.25 & $(61.05,24.42)$ & 4.75 & 1.00 \\
\hline 1050 & 3.00 & $(43.60,43.60)$ & 2.25 & $(65.40,26.16)$ & 4.75 & 1.00 \\
\hline
\end{tabular}

\section{AE Characteristics of Coal at Different Depths under Triaxial Unloading}

AE signals excited by microfracture events inside coal samples were collected in real time and characterized by AE characteristic parameters such as AE counts, AE events, AE energy, amplitude, duration, and rise time [34]. By analyzing these AE parameters, the AE characteristics of typical coal samples at different depths under triaxial unloading were studied, which is helpful to further understand the unloading failure characteristics of coal at different depths under mining disturbance. 


\subsection{AE Temporal Characteristics at Different Depths}

Figure 4 shows the relationship between the AE characteristic parameters and axial stress with respect to time for typical coal samples at different depths under triaxial unloading. The results show that the cumulative AE counts of the coal samples increase in a smooth curve, and the cumulative AE energy increases in a "step" manner. The AE temporal characteristics of coal samples at different depths under triaxial unloading have similar characteristics. In the first unloading stage, the confining pressure is unloaded, the axial pressure is loaded from the hydrostatic state, and the coal samples in this stage are still restrained by a high confining pressure when the cumulative AE energy curve and the cumulative AE count curve approach zero and the AE signals are very quiet. After entering the second unloading stage, the rate of unloading confining pressure is constant, the rate of loading axial pressure increases, and the $\mathrm{AE}$ phenomenon begins to appear. AE counts increase slowly and $\mathrm{AE}$ energy releases gradually. As the unloading time increases, the axial pressure continues to increase, the confining pressure continues to decrease, the AE activity level increases significantly, the AE counts accumulate rapidly, and the AE energy release accelerates. In the vicinity of the peak stress, the AE count rate and AE energy rate increase sharply, and then a stress drop occurs inside the coal samples, indicating that the coal samples are about to undergo macroscopic failure and instability. The AE temporal characteristics adequately reflect the triaxial unloading failure process of coal samples at different depths and can make a reliable early warning for unloading failure of coal under mining disturbances, which has an important engineering guiding significance for the instability prediction of the surrounding rock of roadways in deep coal mines.

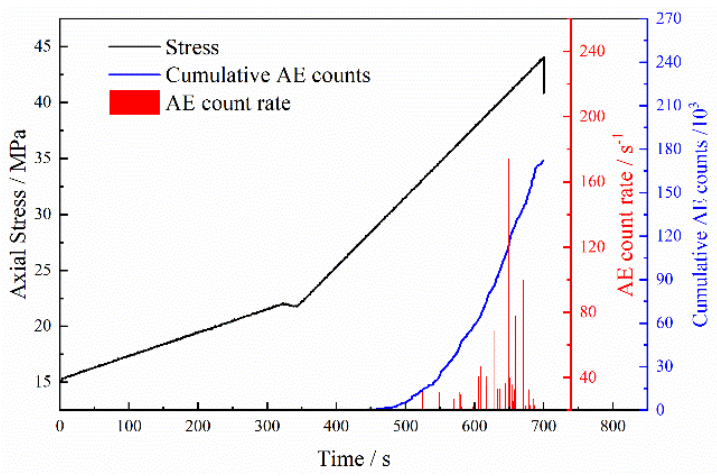

(a1)

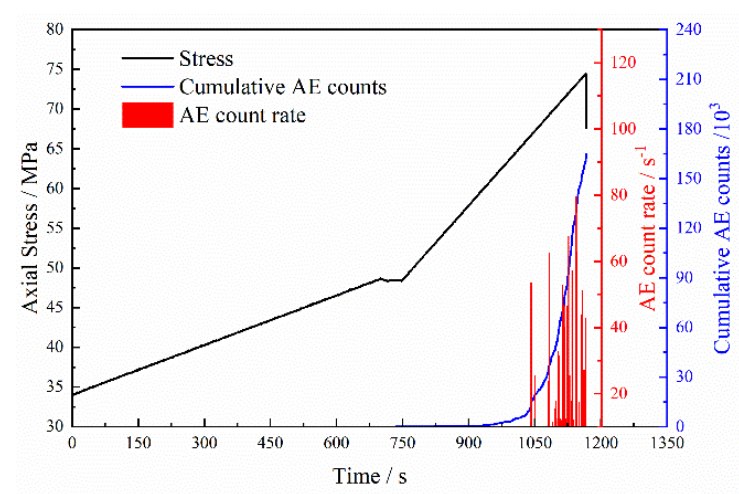

(b1)

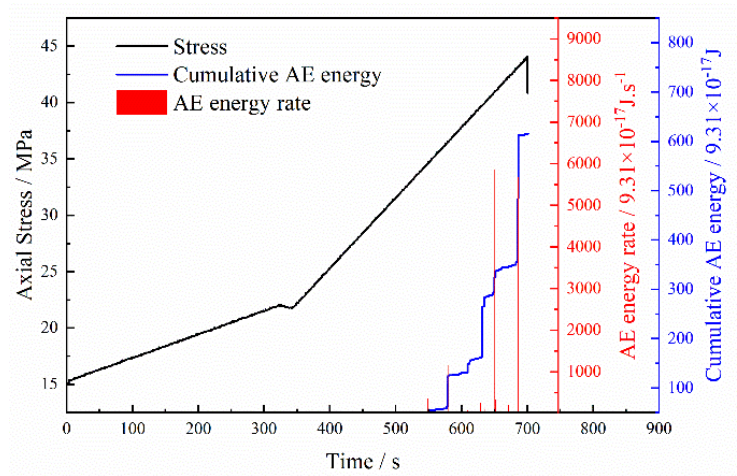

(a2)

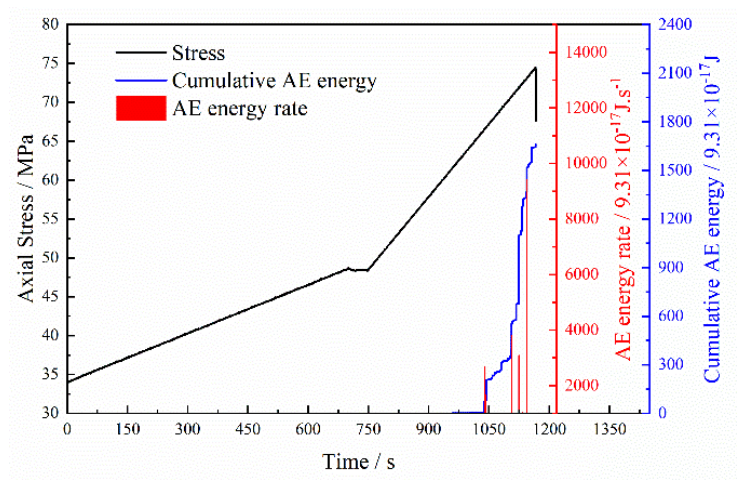

(b2)

Figure 4. Cont. 


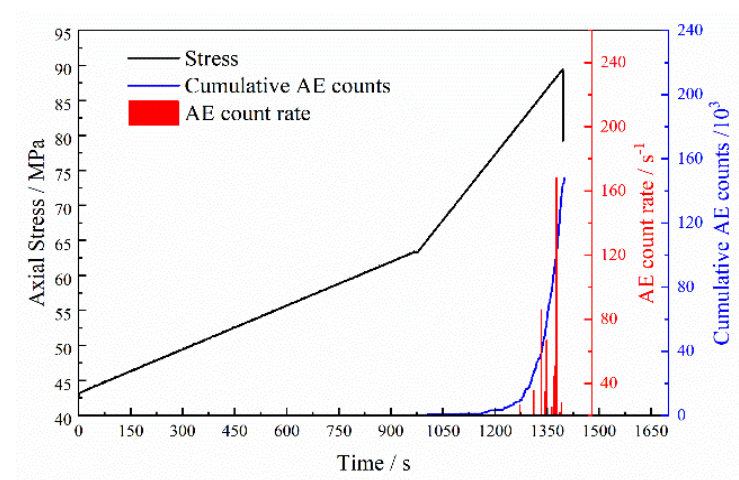

(c1)

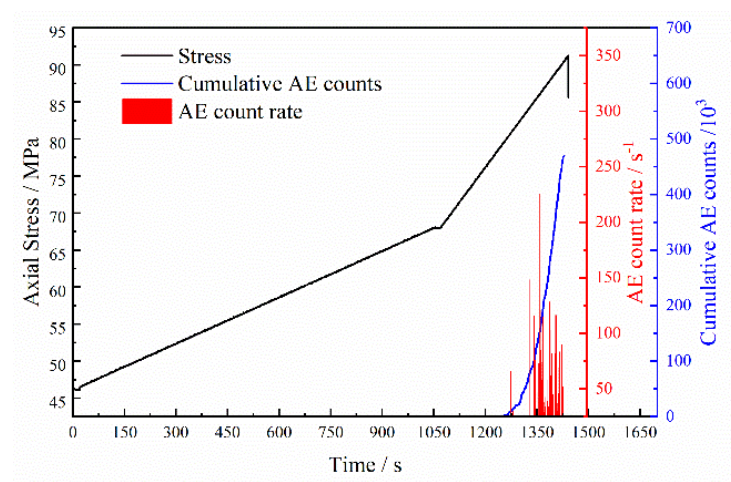

(d1)

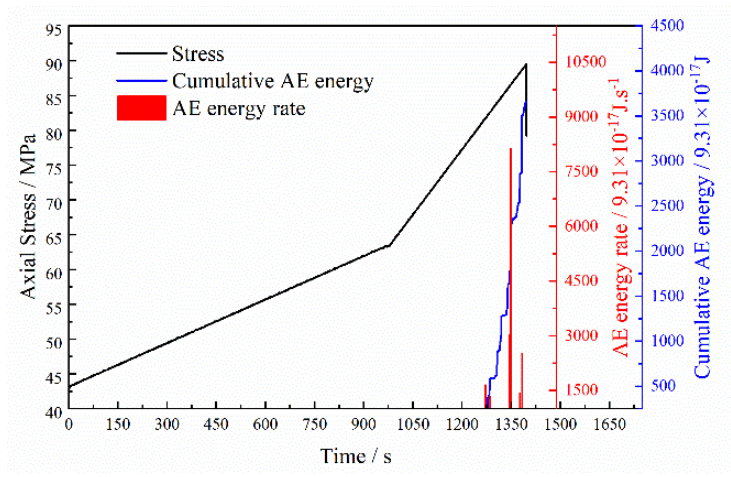

(c2)

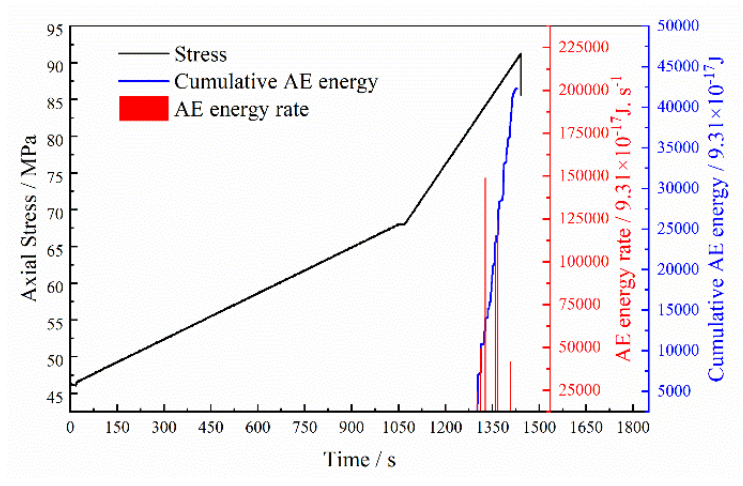

(d2)

Figure 4. AE temporal characteristic parameter and deformation evolution process of coal samples at different depths: (a1) $300 \mathrm{~m}$ (cumulative AE counts and AE count rate), (a2) $300 \mathrm{~m}$ (cumulative AE energy and AE energy rate), (b1) $600 \mathrm{~m}$ (cumulative AE counts and AE count rate), (b2) $600 \mathrm{~m}$ (cumulative AE energy and AE energy rate), (c1) $850 \mathrm{~m}$ (cumulative AE counts and AE count rate), (c2) $850 \mathrm{~m}$ (cumulative AE energy and AE energy rate), (d1) $1050 \mathrm{~m}$ (cumulative AE counts and AE count rate), and (d2) $1050 \mathrm{~m}$ (cumulative AE energy and AE energy rate).

Figure 5 shows how the cumulative AE counts and cumulative AE energy of typical coal samples at different depths vary with respect to the axial stress level. As shown in Figure $5 \mathrm{a}$, the AE counts of the 300-m coal sample begin to increase at an axial stress level of approximately $70 \%$, and the AE count of the $1050-\mathrm{m}$ coal sample is approximately $87 \%$. However, the AE counts of the 1050-m coal sample grow more rapidly, and the cumulative AE counts of the 1050-m coal sample are 2.7 times that of the 300-m coal sample. According to the cumulative AE counts, the AE events in deep coal occur later than those in shallow coal under mining unloading conditions; however, the AE activity level and activity intensity are higher in deep coal.

As shown in Figure 5b, the axial stress levels of the 300-m, 600-m, 850-m, and 1050-m coal samples that correspond to the initial release of AE energy are approximately $64 \%, 73 \%, 75 \%$, and $86 \%$, respectively. With increasing depth, the "step" accumulation of AE energy gradually weakens in the coal samples under triaxial unloading, and the cumulative AE energy released increases. The cumulative AE energy of the 1050-m coal sample is approximately 69 times that of the 300-m coal sample. Moreover, during the unloading process before the $90 \%$ axial stress level, the AE energy released from the deep coal sample is lower than that released from the shallow coal sample; after the $90 \%$ axial stress level, the situation is opposite, which shows that the AE energy is released rapidly in the high stress level stage. According to the AE energy, the energy released from the deep coal occurs later than that released from the shallow coal under mining unloading conditions. However, the cumulative energy released is greater and the release process is more concentrated in deep coal, indicating that the 
energy released from deep coal is more rapid. The study of Yang et al. also showed that the AE energy release of coal taken from the Pingdingshan 10 mine was more concentrated under high confining pressure [17]. Therefore, presplitting measures should be taken to release the stored energy of deep coal seams in the Pingdingshan coal mine area before mining.

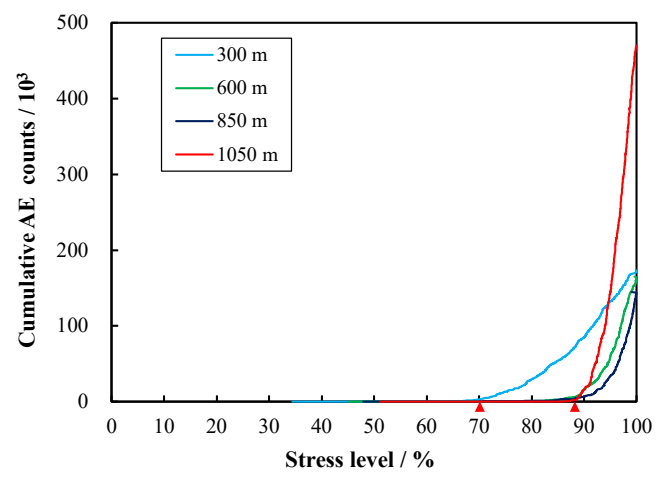

(a)

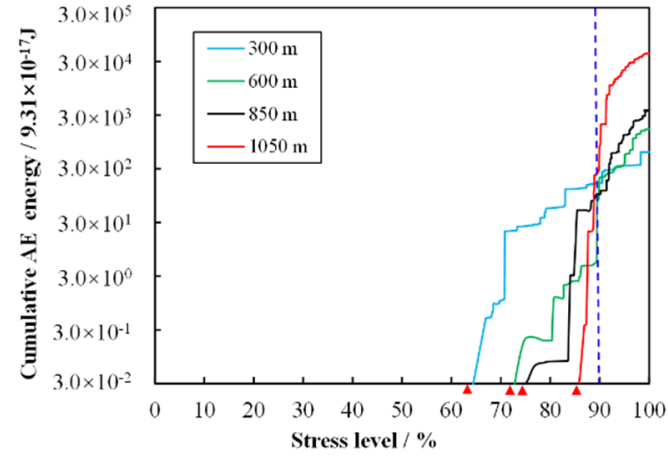

(b)

Figure 5. Variation in the cumulative AE counts and cumulative AE energy of coal samples at different depths with respect to the axial stress level: (a) cumulative AE counts at different depths; (b) cumulative AE energy at different depths.

\subsection{AE Spatial Characteristics and Amplitude Distributions at Different Depths}

The AE events and energy value at the time of failure of the coal samples at different depths are spatially retrieved in Figure 6. In this figure, each sphere represents an AE event. The diameter and color of the sphere represent the energy value of the AE event. A larger sphere and darker color denote a higher energy value. As shown in Figure 6, the AE activity inside the coal samples is very high. The high-energy AE events are mostly distributed near the macroscopic fracture surface of the coal samples. The spatial distribution of AE events has a good correspondence with the destruction morphology of the coal samples. With the increase in the depth, more macroscopic vertical splitting cracks are produced when the deep coal sample is destroyed (Figure 6d), and the number of high-energy AE events inside the coal sample increases. Moreover, the number of high-energy AE events around the macroscopic fracture surface of the coal sample also increases. The spatial distribution of the AE energy release effectively reflects the rupture information of coal.
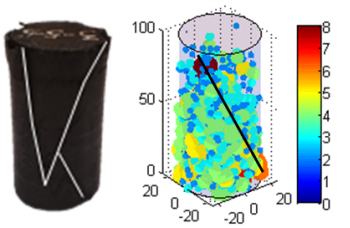

(a)

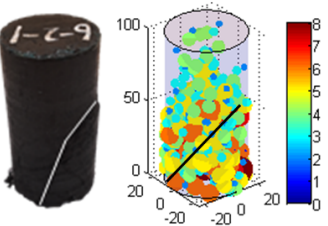

(b)

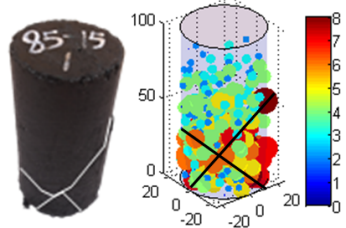

(c)
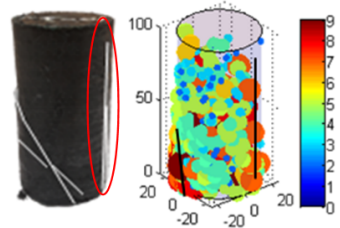

(d)

Figure 6. Destruction morphology and AE energy release spatial distribution of coal samples at different depths: (a) $300 \mathrm{~m}$, (b) $600 \mathrm{~m}$, (c) $850 \mathrm{~m}$, and (d) $1050 \mathrm{~m}$.

AE amplitude represents the strength of AE events and is not affected by thresholds. The analysis of the AE amplitude distribution contributes to a deeper understanding of the evolution characteristics of crack scales during the deformation and failure process of coal samples at different depths. The $b$ value was first used to represent the relationship between the magnitude and frequency of earthquakes [35]. Currently, the study of $b$ values is not limited to seismology. Taking the AE events in the deformation 
and failure of rock as seismic activity (microseism), the $b$ value was used to describe the amplitude distribution characteristics of AE events, and the formula is as follows [36]:

$$
\lg N(A)=C-b \lg A,
$$

where $A$ is the amplitude of the $\mathrm{AE}$ event during the triaxial unloading process $(\mathrm{dB})$, and $N(A)$ is the cumulative $\mathrm{AE}$ events whose amplitude is greater than or equal to $A$ during the triaxial unloading process.

Based on Equation (1), the $b$ value was calculated by fitting the AE amplitude data during the experiment, and the $b$ value evolution characteristics of typical coal samples at different depths under triaxial unloading are shown in Figure 7. Before the peak stress, the $b$ value of the coal samples at all depths increases as the axial stress level increases. This reflects the evolution law that the small-scale microcracks inside the coal sample gradually increase along with the unloading process, which is the result of microcrack propagation inside the coal. In addition, the $b$ value of the coal sample decreases with increasing depth, which shows that the microcrack scale inside deep coal is larger than that inside shallow coal.

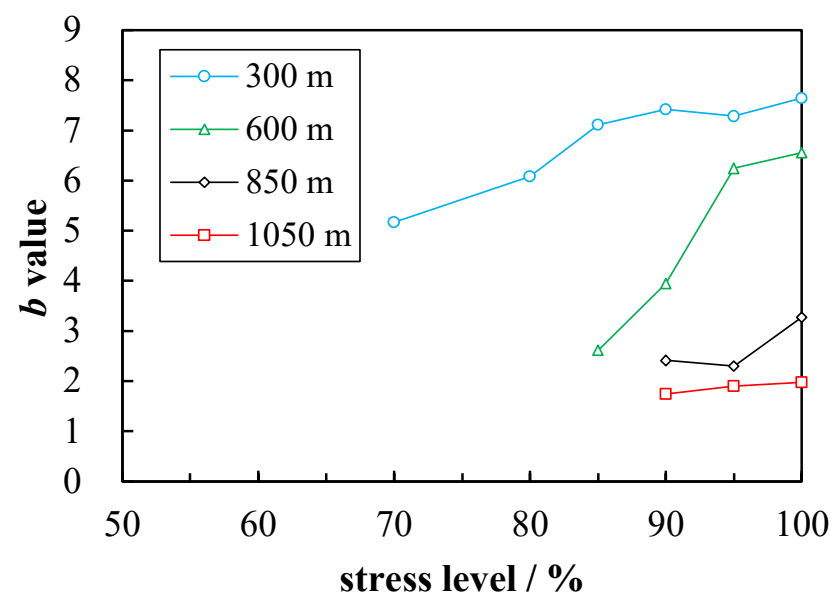

Figure 7. Variation in the $b$ value of coal samples at different depths with respect to the axial stress level.

The study results of the spatial distribution of AE energy release and the evolution characteristics of the $b$ values of coal samples at different depths show that, with the increase in depth, the cracks inside coal gradually change from small-scale, low-energy cracks (shallow coal) to large-scale, high-energy cracks (deep coal). Cracks inside deep coal samples are more easily integrated into nucleation driven by energy, which results in an increase in the severity of unloading failure and rupture degree of deep coal. These findings reflect the changes in the AE characteristics of shallow and deep coal.

\section{Crack Evolution and Failure Behavior of Coal at Different Depths under Triaxial Unloading}

At present, most studies on coal failure behavior or failure modes remain in the phenomenological description of the destruction morphology of coal samples [5-8], and the mechanical mechanism analysis of coal failure behavior that takes comprehensive consideration of the mining disturbance influence and the depth is still lacking. Through the processing and analysis of AE signals, the failure behavior of coal samples at different depths under mining unloading conditions was studied from the perspective of tensile and shear crack evolution, which is of great significance to reveal the cause and mechanism of deep mining disasters.

\subsection{Crack Classification Based on AE Parameters}

Based on the crack classification method proposed by Ohtsu [23], the tensile and shear failure behavior of typical coal samples at different depths under triaxial unloading conditions were studied. 
Specifically, according to the combination of the four types of AE characteristic parameters of rise time, amplitude, AE counts, and duration, the $R A$ value and $A F$ value are defined as follows:

$$
\begin{aligned}
& R A=\text { rise time/amplitude }, \\
& A F=A E \text { counts/duration } .
\end{aligned}
$$

In general, the initiation of tensile cracks in rock materials mostly has high $A F$ values and low $R A$ values, whereas shear cracks have the characteristics of high $R A$ values and low $A F$ values. As shown in Figure 8, based on the studies of Liu [10], Yao [11], Ohtsu [23], and He [28], RA-AF correlation analysis was used to classify the cracking mode of the coal samples $(A F: R A=1)$. Accordingly, the classification results of the cracking mode during triaxial unloading of typical coal samples at different depths are shown in Figure 9. It should be noted that, since the AE signal in the first unloading stage of the coal samples at four depths was not detected, Figure 9 shows the tensile and shear cracks in the second unloading stage. Figure 9a-d intuitively show that, with the increase in depth, the axial stress level where the tensile and shear cracks begin to emerge increases, and the tensile and shear cracks tend to be more concentrated in high-axial-stress areas. In addition, compared to shallow coal samples, deep coal samples have a higher number of tensile cracks with high $A F$ values and a lower number of shear cracks with high $R A$ values, which shows that, with increasing depth, the tensile cracks in the coal gradually occupy a dominant position in quantity. The above analysis qualitatively reflects the differences in the tensile and shear crack evolution characteristics of deep and shallow coal under triaxial unloading.

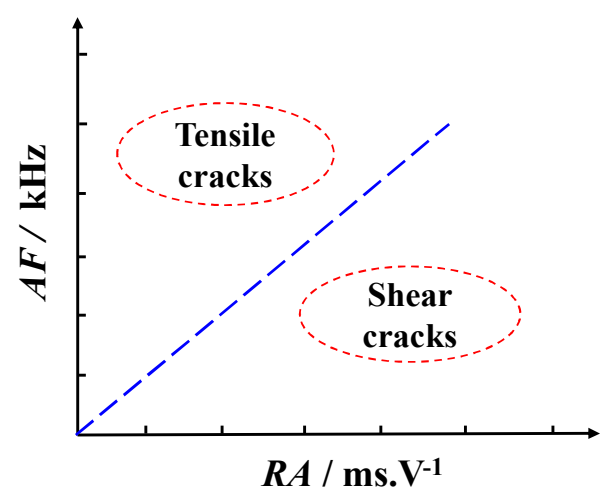

Figure 8. Crack classification based on $A F-R A$ correlation analysis.

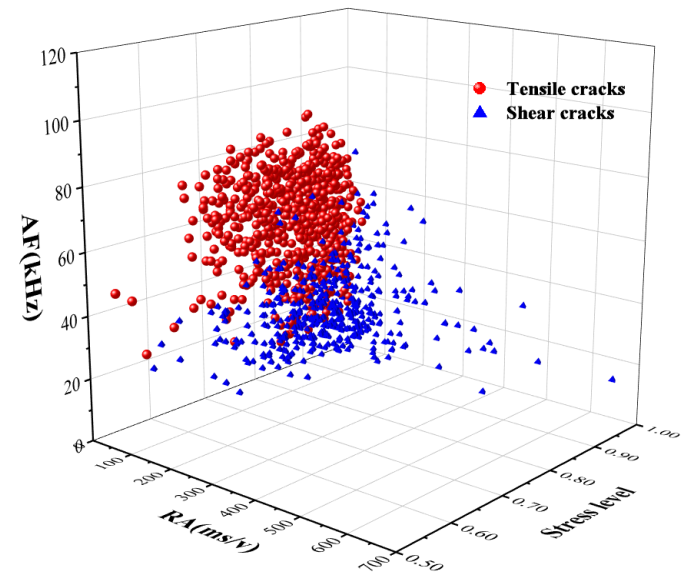

(a)

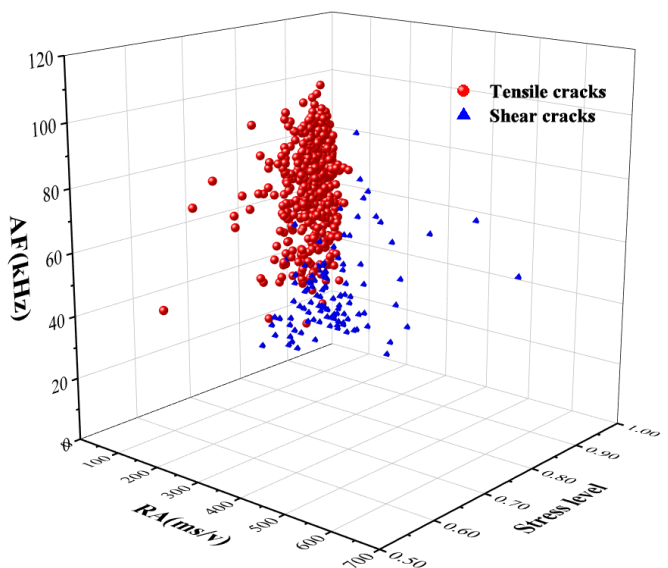

(b)

Figure 9. Cont. 


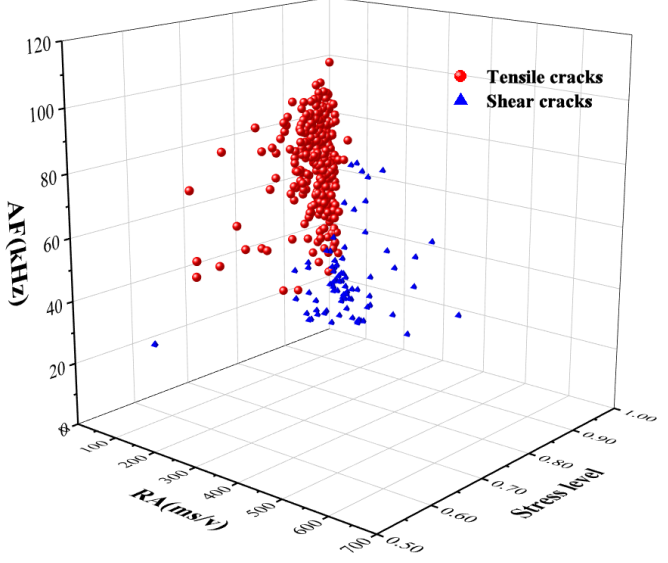

(c)

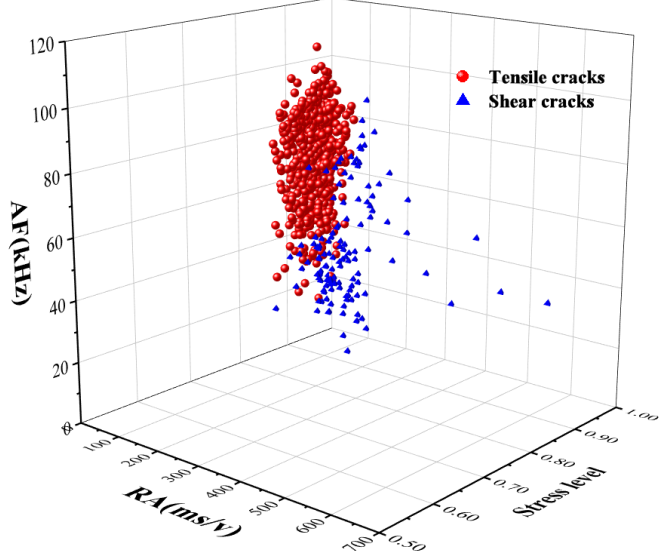

(d)

Figure 9. Variation in the tensile cracks and shear cracks of coal samples at different depths with respect to the axial stress level: (a) $300 \mathrm{~m},(\mathbf{b}) 600 \mathrm{~m}$, (c) $850 \mathrm{~m}$, and (d) $1050 \mathrm{~m}$.

\subsection{Crack Spatial-Temporal Evolution and Failure Behavior of Coal at Different Depths}

To study the difference in unloading failure behavior of coal samples at different depths, the percentages of tensile and shear cracks in four stress stages (before $80 \%$ axial stress level, $80-90 \%$, 90-95\%, and $95-100 \%$ ) and in the whole process for coal samples at different depths under triaxial unloading were further determined, as shown in Table 2. It should be noted that, since the 1050-m coal sample did not appear the AE signal before the $80 \%$ stress level, it can be considered that there was no initiation of tensile and shear crack inside the 1050-m coal sample in this stress stage $[23,26]$. Therefore, Table 2 does not provide the tensile and shear crack percentage in the stress stage "before $80 \%$ " for the 1050-m coal sample. The development degree of tensile cracks in the coal samples at four depths under triaxial unloading is higher than that of shear cracks, and the statistical characteristics of the tensile and shear crack evolution have an obvious correlation with the depth.

Table 2. Tensile crack percentage and shear crack percentage of coal samples at different depths.

\begin{tabular}{ccccccccccc}
\hline $\begin{array}{c}\text { Depth } \\
(\mathbf{m})\end{array}$ & \multicolumn{2}{c}{ Before $\mathbf{8 0} \%$} & \multicolumn{2}{c}{$\mathbf{8 0 - 9 0 \%}$} & \multicolumn{2}{c}{$\mathbf{9 0 - 9 5 \%}$} & \multicolumn{2}{c}{$\mathbf{9 5 - 1 0 0 \%}$} & \multicolumn{2}{c}{ Overall Process } \\
\cline { 2 - 10 } & $\begin{array}{c}\text { Tensile } \\
\mathbf{\%}\end{array}$ & $\begin{array}{c}\text { Shear } \\
\mathbf{\%}\end{array}$ & $\begin{array}{c}\text { Tensile } \\
\mathbf{\%}\end{array}$ & $\begin{array}{c}\text { Shear } \\
\mathbf{\%}\end{array}$ & $\begin{array}{c}\text { Tensile } \\
\mathbf{\%}\end{array}$ & $\begin{array}{c}\text { Shear } \\
\mathbf{\%}\end{array}$ & $\begin{array}{c}\text { Tensile } \\
\mathbf{\%}\end{array}$ & $\begin{array}{c}\text { Shear } \\
\mathbf{\%}\end{array}$ & $\begin{array}{c}\text { Tensile } \\
\mathbf{\%}\end{array}$ & $\begin{array}{c}\text { Shear } \\
\mathbf{\%}\end{array}$ \\
\hline 300 & 67.91 & 32.09 & 64.68 & 35.32 & 60.19 & 39.81 & 52.94 & 47.06 & 61.60 & 38.40 \\
600 & 83.33 & 16.67 & 74.67 & 25.33 & 81.87 & 18.13 & 81.73 & 18.27 & 80.89 & 19.11 \\
850 & 87.50 & 12.50 & 80.00 & 20.00 & 79.10 & 20.90 & 81.13 & 18.87 & 80.88 & 19.12 \\
1050 & - & - & 81.82 & 18.18 & 86.67 & 13.33 & 84.39 & 15.61 & 85.05 & 14.95 \\
\hline
\end{tabular}

Figure 10 shows the tensile crack percentage of typical coal samples at specific depths during different stress stages. Figure 11 shows the cumulative tensile crack percentage in the overall triaxial unloading process of typical coal samples at different depths. As shown in Figure 10, when the depth is constant, as the axial stress level increases, the tensile crack percentage of the $300-\mathrm{m}$ coal sample shows a decreasing trend (the decrease is $14.97 \%$ ), the $600-\mathrm{m}$ and $850-\mathrm{m}$ coal samples decrease first and then increase, and the 1050-m coal sample generally increases. As the depth increases, the tensile crack percentage of the coal sample in each stress stage increases, and, in the stress stage (95-100\%) near the coal failure, the difference between the tensile crack percentage of the deep and shallow coal samples is significantly higher than that in the other stress stages. In addition, the cumulative tensile crack percentage in the overall triaxial unloading process of the coal sample shows a trend of increasing with increasing depth; the cumulative tensile crack percentage is $61.60 \%$ for the $300-\mathrm{m}$ coal sample and $85.05 \%$ for the $1050-\mathrm{m}$ coal sample, which is an increase of approximately $23.45 \%$, as shown in Figure 11 . 
The above results show that there are significant differences in the crack evolution characteristics during the triaxial unloading of coal at different depths. A greater depth results in more complete tensile crack propagation near the unloading failure of coal.

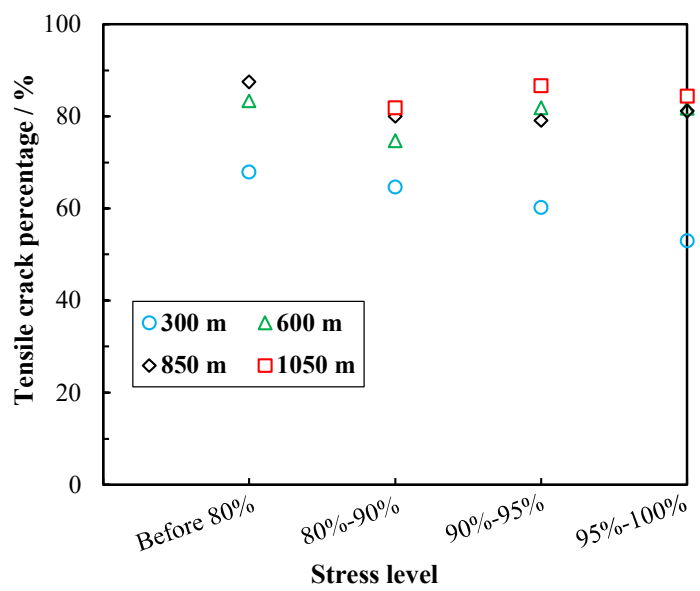

Figure 10. Tensile crack percentage during different stress stages of the coal sample at specific depths.

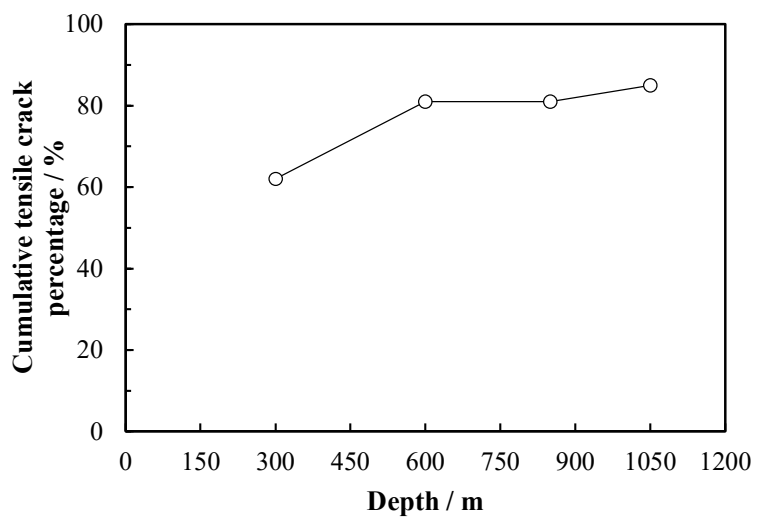

Figure 11. Cumulative tensile crack percentage in the overall triaxial unloading process of coal samples at different depths.

Figure 12 shows the spatial distribution characteristics of tensile and shear events and AE energy during different stress stages of typical coal samples at different depths. In Figures 10 and 12, based on the spatial-temporal evolution characteristics of tensile and shear cracks, the differences in the failure behavior of coal at different depths are shown below.

For the $300-\mathrm{m}$ coal sample, in the initial stage of crack development (before $80 \%$ axial stress level), the number of tensile cracks formed is higher than the number of shear cracks formed. As the unloading progresses, the percentage of tensile cracks decreases continuously (80-90\%). During the stress stage near coal failure (95-100\%), the percentages of tensile cracks and shear cracks are similar (the tensile crack percentage is $52.94 \%$, whereas the shear crack percentage is $47.06 \%$ ), and no nucleation of tensile or shear cracks is observed inside the coal sample (as shown in Figure 12a), indicating that the failure behavior of the $300-\mathrm{m}$ coal sample is controlled jointly by tensile and shear cracks and, finally, tensile-shear composite failure occurs.

The spatial-temporal evolution of the tensile and shear cracks in the 600-m and 850-m coal samples has similar characteristics. Crack development is dominated by tensile cracks during the initial stage (before axial stress level 80\%), and, as the unloading continues, the shear crack percentage increases during the $80-90 \%$ stress stage (the percentage is still below $25 \%$ ) and decreases during the $90-100 \%$ stress stage. The nucleation phenomenon of tensile cracks appears at the bottom of the coal sample and that of the $850-\mathrm{m}$ coal sample is more obvious than that of the $600-\mathrm{m}$ coal sample (Figure $12 \mathrm{~b}, \mathrm{c}$ ). 
This finding shows that, with the increase in depth, the 600-m and 850-m coal samples gradually change to exhibit tensile failure behavior caused by the propagation of tensile cracks.

Before $80 \%$

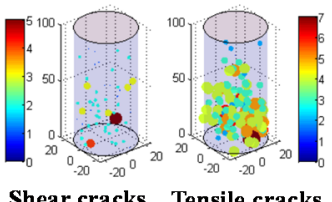

Shear cracks Tensile cracks

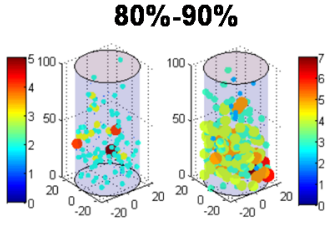

Shear cracks Tensile cracks

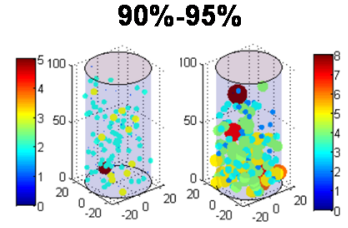

Shear cracks Tensile cracks

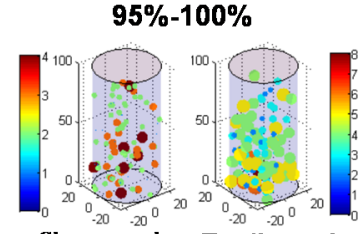

Shear cracks Tensile cracks

(a)

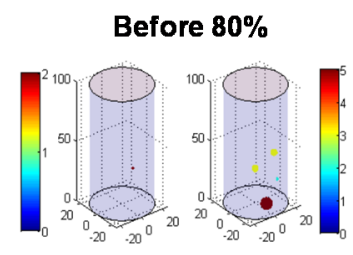

Shear cracks Tensile cracks

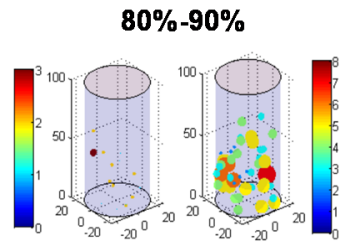

Shear cracks Tensile cracks

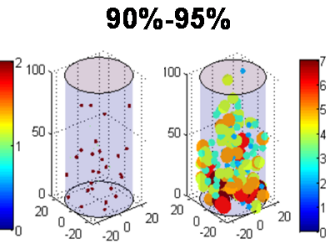

Shear cracks Tensile cracks

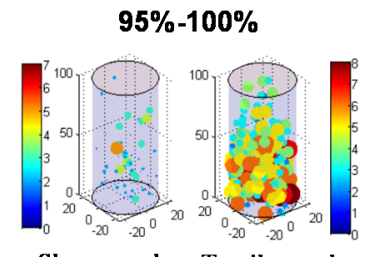

Shear cracks Tensile cracks

(b)

Before $80 \%$

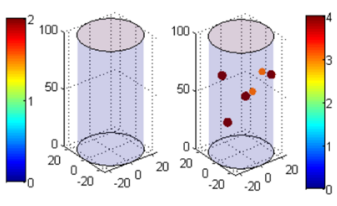

Shear cracks Tensile cracks

Before $80 \%$

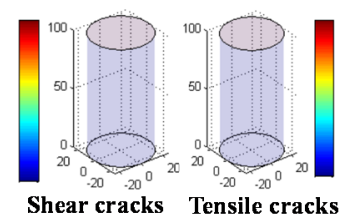

$80 \%-90 \%$

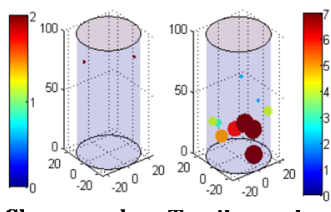

Shear cracks Tensile cracks

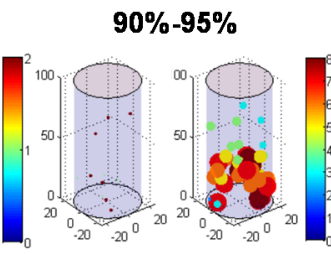

Shear cracks Tensile cracks

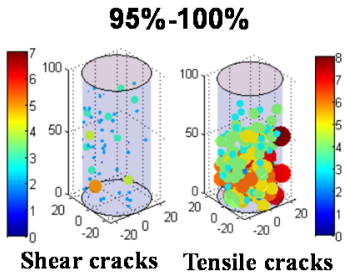

Shear cracks Tensile cracks

(c)

$80 \%-90 \%$

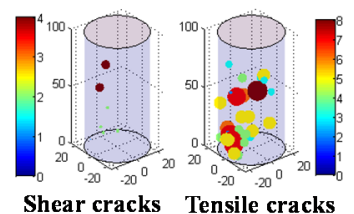

$90 \%-95 \%$

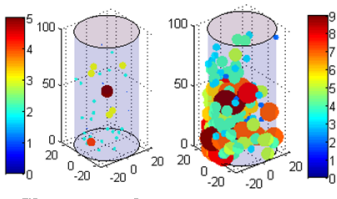

Shear cracks Tensile cracks
95\%-100\%

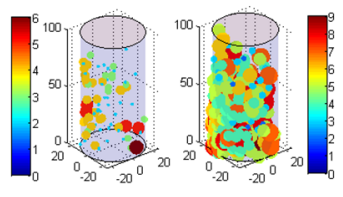

Shear cracks Tensile cracks

(d)

Figure 12. Spatial distribution of tensile and shear events during different stress stages of coal samples at different depths: (a) $300 \mathrm{~m}$, (b) $600 \mathrm{~m}$, (c) $850 \mathrm{~m}$, and (d) $1050 \mathrm{~m}$.

For the 1050-m coal sample, the tensile crack percentage generally increases as the unloading progresses and reaches $84.39 \%$ near the peak axial stress. During the triaxial unloading process, the tensile crack percentage in each stress stage is higher than $80 \%$, and the crack propagation inside the coal sample is mainly controlled by the tensile cracks. Moreover, compared with coal samples at other depths, the 1050-m coal sample exhibits a more obvious nucleation phenomenon of tensile cracks (as shown in Figure 12d). These results indicate that significant tensile failure behavior occurs in the 1050-m coal, which corresponds to the phenomenon that more macroscopic vertical splitting cracks appear in the final destruction morphology of the 1050-m coal sample than in that of the coal samples at other depths (as shown in Figure 6).

Furthermore, the failure behavior of coal samples at different depths is analyzed from the AE energy characteristics of tensile and shear fractures. According to AE energy, microfracture events in coal samples are distinguished into three types: low-energy fractures $\left(0-10^{3} \mathrm{E}_{\text {unit }}\right)$, medium-energy fractures $\left(10^{3}-10^{6} E_{\text {unit }}\right)$, and high-energy fractures $\left(>10^{6} E_{\text {unit }}\right)$, where the $E_{\text {unit }}$ is defined as the unit of fracture AE energy, and $1 \mathrm{E}_{\mathrm{unit}}=9.31 \times 10^{-22} \mathrm{~J}$. In addition, the number of various types of 
microfractures in coal samples at different depths under triaxial unloading is counted (as shown in Table 3).

Table 3. Statistics of tensile and shear fractures with different AE energy value inside coal samples at different depths.

\begin{tabular}{|c|c|c|c|c|c|c|c|c|}
\hline \multirow{2}{*}{$\begin{array}{l}\text { Depth } \\
\text { (m) }\end{array}$} & \multirow{2}{*}{$\begin{array}{l}\text { Fracture } \\
\text { Mode }(n)\end{array}$} & \multicolumn{3}{|c|}{ Low-Energy Fracture $\left(E_{\text {unit }}\right)$} & \multicolumn{3}{|c|}{ Medium-Energy Fracture $\left(E_{u n i t}\right)$} & \multirow{2}{*}{$\begin{array}{l}\text { High-Energy } \\
\text { Fracture ( } \mathrm{E}_{\text {unit }} \\
>10^{6}\end{array}$} \\
\hline & & $0-10$ & $10-10^{2}$ & $10^{2}-10^{3}$ & $10^{3}-10^{4}$ & $10^{4}-10^{5}$ & $10^{5}-10^{6}$ & \\
\hline \multirow{2}{*}{300} & Tensile & 2 & 14 & 79 & 243 & 220 & 99 & 28 \\
\hline & Shear & 0 & 116 & 247 & 52 & 10 & 3 & 0 \\
\hline \multirow{2}{*}{600} & Tensile & 0 & 2 & 43 & 134 & 115 & 116 & 64 \\
\hline & Shear & 0 & 32 & 63 & 12 & 3 & 1 & 1 \\
\hline \multirow{2}{*}{850} & Tensile & 0 & 0 & 11 & 60 & 92 & 68 & 100 \\
\hline & Shear & 0 & 20 & 47 & 7 & 2 & 1 & 1 \\
\hline \multirow{2}{*}{1050} & Tensile & 0 & 1 & 24 & 70 & 214 & 151 & 289 \\
\hline & Shear & 0 & 10 & 68 & 18 & 25 & 7 & 1 \\
\hline
\end{tabular}

Note: $E_{u n i t}$ is defined as the unit of fracture AE energy, where $1 E_{\text {unit }}=9.31 \times 10^{-22} \mathrm{~J}$.

As shown in Table 3, the shear fractures in the 300-m and 600-m coal samples are mainly low-energy fractures and medium-energy fractures, among which the tensile fractures are mainly medium-energy fractures, but the number of high-energy tensile fractures in the 600-m coal sample is more than that in the 300-m coal sample. The shear fractures in the $850-\mathrm{m}$ and $1050-\mathrm{m}$ coal samples are mainly low-energy fractures, whereas the tensile fractures are mainly medium-energy fractures and high-energy fractures. At the same time, the number of medium-energy tensile fractures and high-energy tensile fractures in the 1050-m coal sample increases significantly compared to coal samples at other depths. Deep coal has more medium-energy or high-energy tensile fractures than shallow coal, indicating that, as the depth increases, more energy of the coal system is used to drive the fracture to expand along the direction of principal stress to form more vertical tensile cracks. Moreover, a previous study showed that the fracture mechanism of coal sample was transformed under the effect of external stress, and the unloading confining pressure promoted the initiation and development of tensile crack inside coal [17]. The unloading process of the confining pressure of the deep coal is longer than that of the shallow coal, resulting in a larger number of tensile cracks that developed inside the deep coal compared to the shallow coal. Consequently, deep coal was more prone to suffer tensile failure.

The above analysis reveals the depth effect on failure behavior of coal under mining unloading conditions, which can be applied to the evaluation and control of stability of roadway surrounding rock at different depths in the Pingdingshan coal mine area.

\section{Damage Characteristics of Coal at Different Depths under Triaxial Unloading}

In the process of deep coal mining, mine accidents caused by damage accumulation and the development of coal rock masses occasionally occur $[4,37,38]$. The damage characteristics in the unloading process of coal at different depths were analyzed, which can provide useful guidance for the stability control of the surrounding rock that is disturbed in deep roadways and the efficient extraction of gas in the coal seam.

\subsection{Damage Analysis Method Based on AE Parameters}

Kachanov defined the damage variable as follows [39]:

$$
D=\frac{S_{d}}{S}
$$


where $S_{d}$ is the cross-sectional area of damage, and $S$ is the cross-sectional area of nondestructive material at the initial stage.

Considering that the cumulative $\mathrm{AE}$ count is $A_{c}$ when the cross-sectional area $S$ of nondestructive material completely loses its bearing capacity, the cumulative AE count of the coal sample per unit area is $A_{t}=A_{c} / S$. When the cross-sectional area of damage reaches $S_{d}$, the cumulative AE count is $A_{d}=A_{t} S_{d}=A_{c} S_{d} / S$. Therefore, the rock damage variable $D$ based on AE counts can be calculated according to the following formula [19]:

$$
D=\frac{S_{\mathrm{d}}}{S}=\frac{A_{d}}{A_{c}},
$$

From the mesoscale perspective, rock damage manifests as the propagation of microcracks [40]. To show the crack evolution characteristics in the process of coal damage more intuitively and reflect the contribution degree of tensile and shear crack propagation to coal damage, the AE events of tensile and shear cracks in coal samples at different depths under triaxial unloading were processed as follows:

$$
N_{t}=\frac{N_{t d}}{N_{c}}, N_{s}=\frac{N_{s d}}{N_{c}},
$$

where $N_{t d}$ and $N_{s d}$ are cumulative tensile AE events and cumulative shear AE events of the coal sample before one point in time under triaxial unloading, respectively, and $N_{c}$ is the cumulative AE events of the coal sample in the whole process of triaxial unloading.

\subsection{Damage Characteristics of Coal at Different Depths}

According to the above damage analysis method, the damage evolution curve and the crack propagation curve of typical coal samples at different depths are obtained (as shown in Figure 13). The damage evolution process of coal samples at different depths under triaxial unloading presents a "three stage" feature:

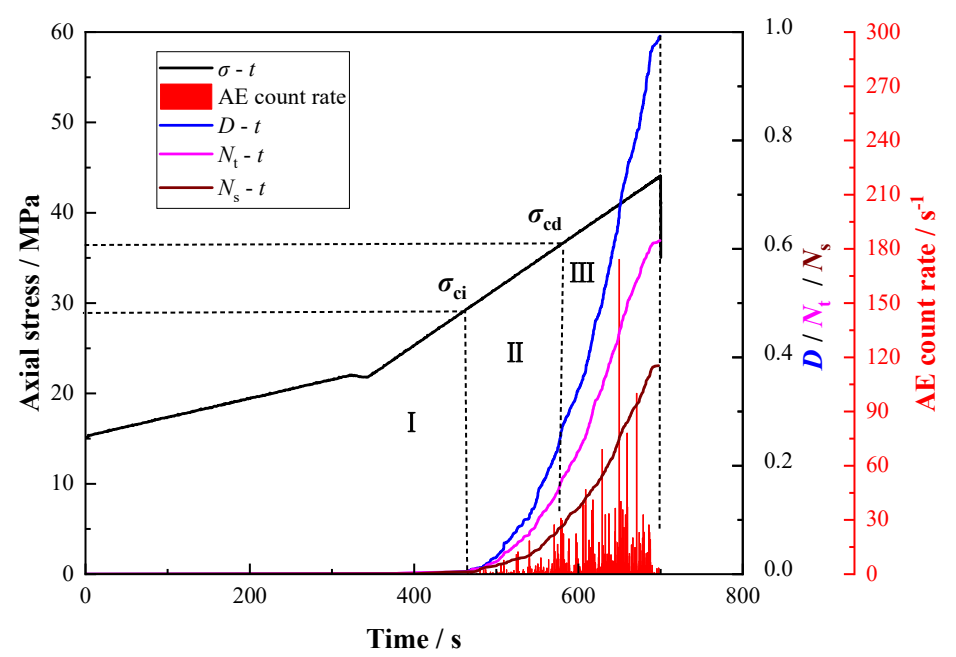

(a)

Figure 13. Cont. 


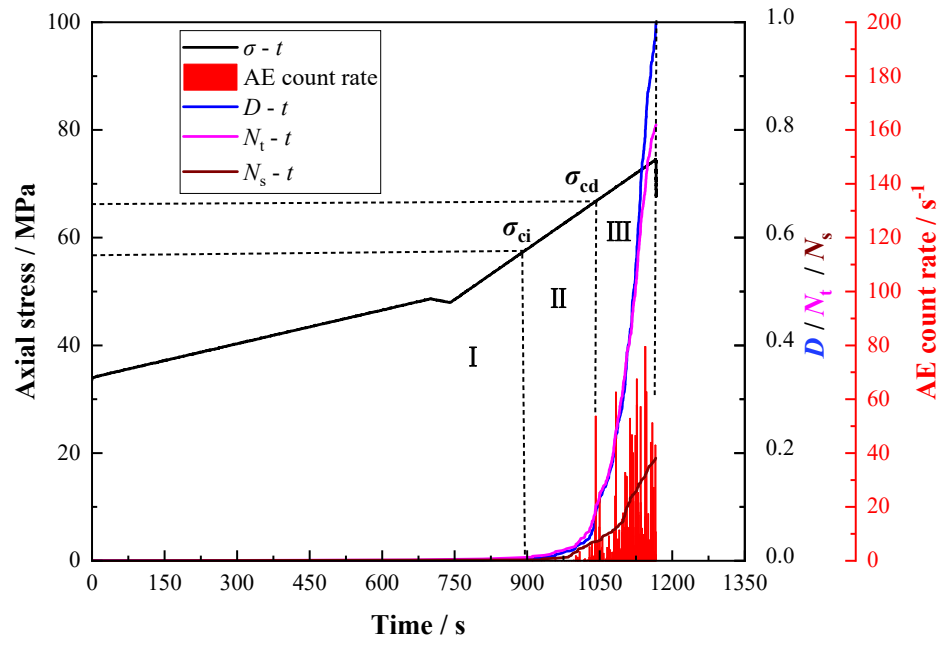

(b)

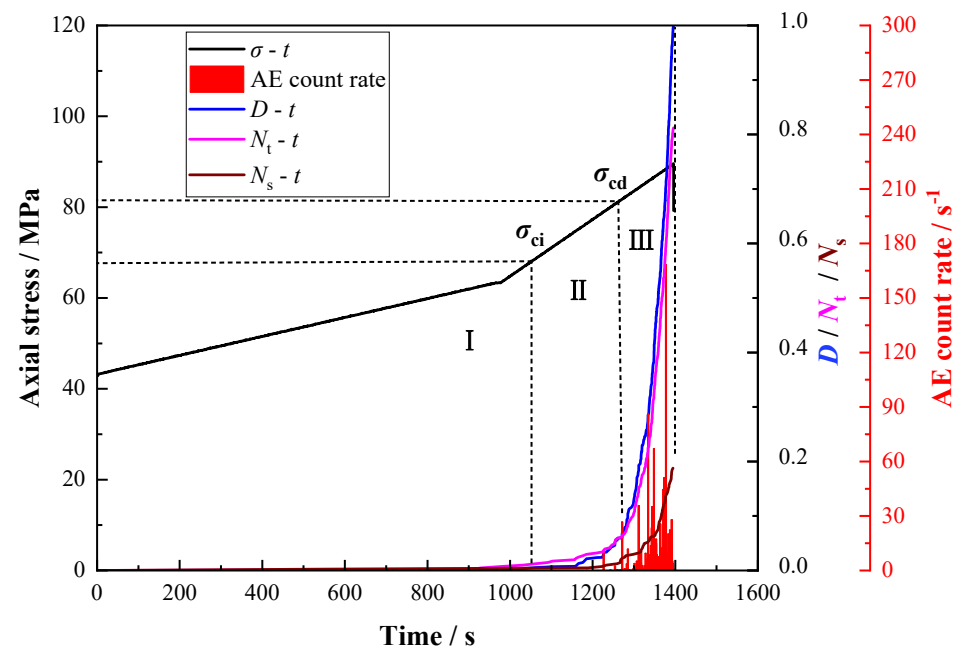

(c)

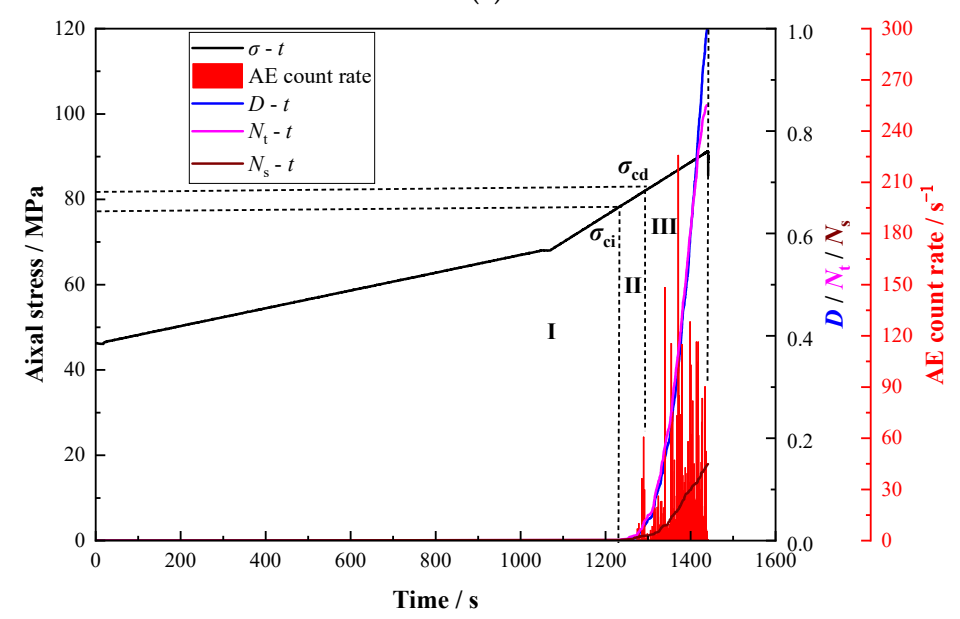

(d)

Figure 13. Crack propagation and damage evolution of coal samples at different depths under triaxial unloading: (a) $300 \mathrm{~m}$, (b) $600 \mathrm{~m}$, (c) $850 \mathrm{~m}$, and (d) $1050 \mathrm{~m}$. 
(1) The elastic stage without crack initiation (I): The axial stress is yet to reach $\sigma_{\mathrm{ci}}$, the primary cracks inside the coal sample are mainly compacted and closed, tensile and shear cracks are not initiated, the damage variable $D$ is 0 , and the coal damage is mainly linear elastic compression.

(2) The stable growth stage of tensile and shear cracks (II): The primary cracks inside the coal sample begin to propagate, new cracks initiate, tensile and shear cracks grow stably, the damage variable $D$ increases slowly, and cracks converge and cause nucleation when the stress reaches $\sigma_{\mathrm{cd}}$.

(3) The unstable growth stage of tensile and shear cracks (III): The tensile and shear cracks inside the coal sample propagate rapidly, the degree of tensile crack propagation is more significant, the damage variable $D$ increases rapidly, and a high number of cracks propagate through to form a macrofracture surface, resulting in the destruction of the coal sample.

As shown in Figure 13a-d, during the three damage stages of the coal samples at different depths, the coal damage caused by the initiation and propagation of tensile cracks is slightly stronger than that caused by the initiation and propagation of shear cracks during stage II, and there is no obvious correlation between their contributions to coal damage and the depth. During stage III leading to coal sample failure, when the axial stress approaches the peak stress, the contribution of tensile crack propagation to coal sample damage is increasingly dominant, and this advantage is more obvious with increasing depth. This finding shows that, with the increase in depth, the damage caused by tensile crack propagation inside the coal sample during mining unloading is more severe, and tensile crack damage occurs more easily, especially near the moment of coal destruction, which is consistent with the above conclusion that deep coal is more prone to tensile failure behavior. The results show that the damage and failure behaviors of the deep coal sample are both easily controlled by tensile cracks in the process of mining unloading. Therefore, in deep coal mining, emphasis should be placed on monitoring and controlling the tensile instability phenomenon, such as when the surrounding rock of the roadway splits and peels off toward the free face.

Crack initiation stress and crack damage stress are the two most commonly used thresholds for describing the process of rock damage. The crack initiation stress $\sigma_{\mathrm{ci}}$ corresponds to when the cracks inside the rock initiate and grow stably, whereas the crack damage stress $\sigma_{\mathrm{cd}}$ corresponds to when the cracks start to grow unstably with the increase in stress [41]. Crack initiation stress $\sigma_{\mathrm{ci}}$ and damage stress $\sigma_{\mathrm{cd}}$ can be determined by the crack volumetric strain method and AE method, and the study of Martin and Cai et al. showed that these two methods have a good correspondence [42,43]. At present, many scholars determine the crack initiation stress $\sigma_{\mathrm{ci}}$ and the crack damage stress $\sigma_{\mathrm{cd}}$ by using the AE method [44].

Based on the AE method proposed by Martin and Cai et al. [42,43], as shown in Figure 13, when the damage variable $D$ starts to increase slowly from 0 and the AE count rate starts to increase slightly, the coal sample enters damage stage II, and the corresponding axial stress is $\sigma_{\mathrm{ci}}$. When the damage variable $D$ begins to increase rapidly and the AE count rate begins to increase dramatically, the coal sample enters damage stage III, and the corresponding axial stress is $\sigma_{\mathrm{cd}}$. Accordingly, the crack initiation stress $\sigma_{\mathrm{ci}}$ and crack damage stress $\sigma_{\mathrm{cd}}$ of coal samples at different depths are obtained as shown in Figure 14. The crack initiation stress level $\left(\sigma_{\mathrm{ci}} / \sigma_{\mathrm{c}}\right)$ of coal at different depths ranges from 0.63 to 0.84 , and the crack damage stress level $\left(\sigma_{\mathrm{cd}} / \sigma_{\mathrm{c}}\right)$ ranges from 0.83 to 0.90 . Previous work indicated that the crack initiation stress level $\left(\sigma_{\mathrm{c}} / \sigma_{\mathrm{c}}\right)$ ranged from $0.3-0.7$ for different types of rocks [45]. Xue et al. [46] analyzed the published results of igneous, metamorphic, and sedimentary rocks and showed that the crack damage stress level $\left(\sigma_{\mathrm{cd}} / \sigma_{\mathrm{c}}\right)$ ranged from $0.73-0.85$. In addition, Tang et al. [47] found that the initial stress level and damage stress level of coal under triaxial compression were $74.53 \%$ and $89.84 \%$, respectively, which are very close to our results.

With increasing depth, the crack initiation stress $\sigma_{\mathrm{ci}}$ and the crack damage stress $\sigma_{\mathrm{cd}}$ increase, the crack initiation stress level $\left(\sigma_{\mathrm{ci}} / \sigma_{\mathrm{c}}\right)$ also increases, and the change in crack damage stress level $\left(\sigma_{\mathrm{cd}} / \sigma_{\mathrm{c}}\right)$ is relatively small. This shows that, in the process of mining unloading, shallow coal is easier to damage than deep coal, and the damage occurs relatively earlier. However, after the damage evolution process of deep and shallow coal samples is further observed (as shown in Figure 13a,d), it can be 
clearly seen that the damage process in stage II (the stable growth stage of tensile and shear cracks) of the 1050-m coal sample is significantly shorter than that of the 300-m coal sample, and the growth rate of the damage variable $D$ in the whole process for the $1050-\mathrm{m}$ coal sample is significantly higher than that for the 300-m coal sample. This shows that, in the process of mining unloading, although the deep coal is damaged at a later point in time, the whole damage process is more rapid, which is consistent with the sudden instability phenomenon of the surrounding rock in the process of deep coal mining.

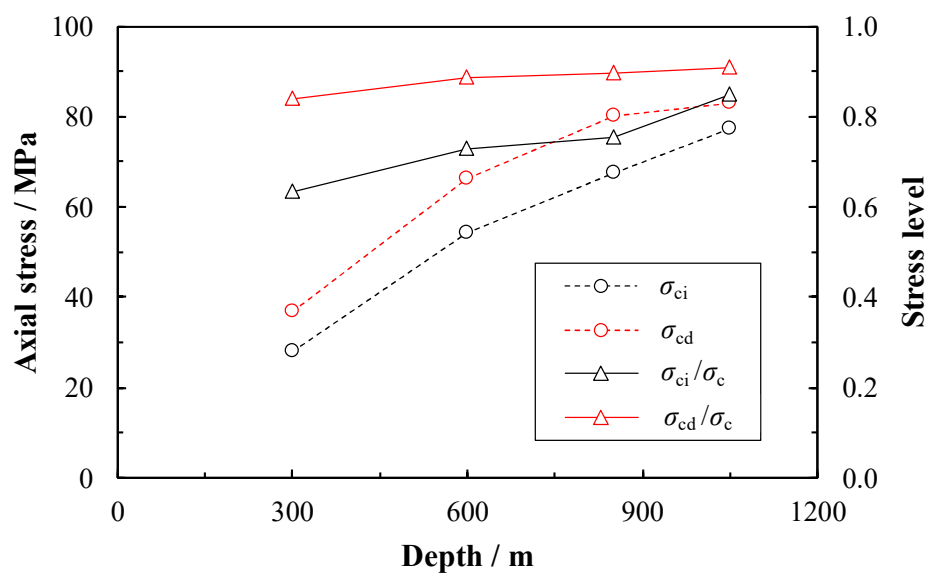

Figure 14. Crack initiation stress $\sigma_{\mathrm{ci}}$ and crack damage stress $\sigma_{\mathrm{cd}}$ of coal samples at different depths.

The above analysis shows that there are significant differences in the damage characteristics of coal at different depths, which, to a certain extent, reflects the differences in fracture characteristics of coal seams at different depths. Those results can be used in determining the range of gas extraction and control of coal and gas outburst in the Pingdingshan coal mine area.

\section{Conclusions}

In this paper, the depth effect on AE characteristics, crack evolution, failure behavior, and damage characteristics of coal under mining unloading condition was systematically explored. The main results are summarized as follows:

(1) There were significant differences in the AE characteristics of coal at different depths during triaxial unloading. AE activities in deep coal were more active and concentrated; the cumulative AE counts of the $1050-\mathrm{m}$ coal sample were 2.7 times that of the $300 \mathrm{~m}$ coal sample. As the depth increased, the cumulative AE energy of coal increased; the cumulative AE energy of the 1050-m coal sample was 69 times that of the 300-m coal sample, and the AE energy release was more rapid. The $b$ value representing the microcrack scale decreased with increasing depth. The severity of unloading failure and the rupture degree of deep coal were higher.

(2) Based on the correlation analysis of AE combination parameters ( $R A$ and $A F)$, the cracking mode of coal were classified, and differences in crack evolution and failure behavior of coal at different depths were revealed. As the axial stress level increased, the tensile crack percentage of the 300-m coal sample showed a decreasing trend, the 600-m and 850-m coal samples decreased first and then increased, and the 1050-m coal sample generally increased. As the depth increased, the cumulative tensile crack percentage of coal increased. The nucleation of tensile crack in deep coal nearing failure was more obvious. Tensile-shear composite failure occurred in the 300-m coal sample, whereas significant tensile failure occurred in the 1050-m coal sample.

(3) Based on the damage variable $D$ defined by the AE parameter, the depth effect on the damage evolution of coal was analyzed. The damage evolution of coal was divided into three stages, and the characteristic stress was obtained. As the depth increased, the crack initiation stress level $\left(\sigma_{\mathrm{ci}} / \sigma_{\mathrm{c}}\right)$ increased, and the damage in coal caused by tensile crack propagation became more severe. Deep 
coal was damaged later than shallow coal, but the stable growth stage of tensile and shear cracks was significantly shortened. The damage process of deep coal was more rapid.

It should be noted that the above-mentioned conclusions were only based on the experimental results of coal in this paper, while universal conclusions need to be further verified.

Author Contributions: Conceptualization, A.Z. and Z.J.; methodology, R.Z. and M.G.; software, A.Z. and E.Z.; validation, Z.Z. (Zetian Zhang) and Z.Z. (Zhaopeng Zhang); data curation, M.G.; writing-original draft preparation, A.Z.; writing - review and editing, R.Z., Z.Z. (Zetian Zhang), and A.Z. All authors read and agreed to the published version of the manuscript.

Funding: This research was funded by the National Natural Science Foundation of China (No. U1965203, No. 51804204), the China Postdoctoral Science Foundation (2019T120841), the Applied Basic Research Programs of Sichuan Province (No. 2019YJ0136), and the Open Foundation of the MOE Key Laboratory of Deep Earth Science and Engineering (DUSE201805).

Conflicts of Interest: The authors declare no conflict of interest.

\section{References}

1. Xie, H.P. Research framework and anticipated results of deep rock mechanics and mining theory. Adv. Eng. Sci. 2017, 49, 1-16.

2. Xie, H.P.; Gao, F.; Ju, Y.; Gao, M.Z.; Zhang, R.; Gao, Y.N.; Liu, J.F.; Xie, L.Z. Quantitative definition and investigation of deep mining. J. China Coal Soc. 2015, 40, 1-10.

3. Huang, W.; Chen, Z.Q.; Yue, J.H.; Zhang, Y.; Yang, M. Failure modes of coal containing gas and mechanism of gas outbursts. Min. Sci. Technol. 2010, 20, 504-509. [CrossRef]

4. Li, C.H.; Bu, L.; Wei, X.M.; Wang, P.F.; Shi, Y.Q.; Chen, L.G. Current status and future trends of deep mining safety mechanism and disaster prevention and control. Adv. Eng. Sci. 2017, 39, 4-15.

5. Song, S.L.; Liu, X.S.; Tan, Y.L.; Fan, D.Y.; Ma, Q.; Wang, H.L. Study on failure modes and energy evolution of coal-rock combination under cyclic loading. Shock Vib. 2020, 2020, 1-16. [CrossRef]

6. Fu, Y.; Chen, X.; Feng, Z.L. Characteristics of coal-rock fractures based on CT scanning and its influence on failure modes. J. China Coal Soc. 2020, 45, 568-578.

7. Wu, Y.P.; Gao, X.C. Experimental comparative study on lateral deformation characteristics of coal sample in different loading paths. J. China Coal Soc. 2010, 35, 44-48. [CrossRef]

8. Xue, D.J.; Zhou, H.W.; Wang, Z.H.; Ren, W.G.; Zhang, M.; Liu, Y.Q. Failure mechanism and mining-induced mechanical properties of coal under different loading rates. J. China Coal Soc. 2016, 41, 595-602.

9. Zhang, C.W.; Jin, Z.X.; Feng, G.R.; Song, X.M.; Rui, G.; Zhang, Y.J. Double peaked stress-strain behaviour and progressive failure mechanism of encased coal pillars under uniaxial compression. Rock Mech. Rock Eng. 2020, 53, 3253-3266. [CrossRef]

10. Liu, Y.B.; Yin, G.Z.; Li, M.H.; Zhang, D.M.; Huang, G.; Liu, P.; Zhao, H.G.; Yu, B.C. Mechanical properties and failure behaviour of dry and water-saturated anisotropic coal under true-triaxial loading conditions. Rock Mech. Rock Eng. 2019, 1-20. [CrossRef]

11. Yao, Q.L.; Chen, T.; Tang, C.J.; Sedighi, M. Influence of moisture on crack propagation in coal and its failure modes. Eng. Geol. 2019, 258, 1-12. [CrossRef]

12. Wang, C.Y.; Chang, X.K.; Liu, Y.L.; Chen, S.J. Mechanistic characteristics of double dominant frequencies of Acoustic Emission signals in the entire fracture process of fine sandstone. Energies 2019, 12, 3959. [CrossRef]

13. Lavrov, A. The Kaiser effect in rocks: Principles and stress estimation techniques. Int. J. Rock Mech. Min. Sci. 2003, 40, 151-171. [CrossRef]

14. Liu, J.P.; Li, Y.H.; Xu, S.D.; Jin, C.Y.; Liu, Z.S. Moment tensor analysis of Acoustic Emission for cracking mechanisms in rock with a pre-cut circular hole under uniaxial compression. Eng. Fract. Mech. 2015, 135, 206-218. [CrossRef]

15. Shan, P.F.; Lai, X.P.; Liu, X.M. Correlational analytical characterization of energy dissipation-liberation and acoustic emission during coal and rock fracture inducing by underground coal excavation. Energies 2019, 12, 2382. [CrossRef]

16. Xue, Y.; Dang, F.N.; Cao, Z.Z.; Du, F.; Ren, J.; Chang, X.; Gao, F. Deformation, permeability and acoustic emission characteristics of coal masses under mining-induced stress paths. Energies 2018, 11, 2233. [CrossRef] 
17. Yang, H.M.; Wen, G.C.; Hu, Q.T.; Li, Y.Y.; Dai, L.C. Experimental investigation on influence factors of acoustic emission activity in coal failure process. Energies 2018, 11, 1414. [CrossRef]

18. Shkuratnik, V.L.; Filimonov, Y.L.; Kuchurin, S.V. Experimental investigations into Acoustic Emission in coal samples under uniaxial loading. J. Min. Sci. 2004, 40, 458-464. [CrossRef]

19. Jia, Z.Q.; Xie, H.P.; Zhang, R.; Li, C.B.; Wang, M.; Gao, M.Z.; Zhang, Z.P.; Zhang, Z.Z. Acoustic Emission characteristics and damage evolution of coal at different depths under triaxial compression. Rock Mech. Rock Eng. 2020, 53, 1-14. [CrossRef]

20. Zhang, Z.P.; Zhang, R.; Zhang, Z.T.; Gao, M.Z.; Dai, F. Experimental research on effect of bedding plane on coal Acoustic Emission under uniaxial compression. Chin. J. Rock Mech. Eng. 2015, 34, 770-778.

21. Su, C.D.; Gao, B.B.; Nan, H.; Li, X.J. Experimental study on Acoustic Emission characteristics during deformation and failure processes of coal samples under different stress paths. Chin. J. Rock Mech. Eng. 2009, 28, 757-766.

22. Liu, B.X.; Huang, J.L.; Wang, Z.Y.; Liu, L. Study on damage evolution and Acoustic Emission characteristics of coal-rock uniaxial compression. Chin. J. Rock Mech. Eng. 2009, 28, 3234-3238.

23. Ohtsu, M.; Okamoto, T.; Yuyama, S. Moment tensor analysis of Acoustic Emission for cracking mechanisms in concrete. Aci. Struct. J. 1998, 95, 87-95.

24. Ohtsu, M. Quantitative AE techniques standardized for concrete structures. Adv. Mat. Res. 2006, 13-14, 183-192. [CrossRef]

25. Li, D.S.; Du, F.Z. Monitoring and evaluating the failure behaviour of ice structure using the acoustic emission technique. Cold Reg. Sci. Technol. 2016, 129, 51-59. [CrossRef]

26. Ohno, K.; Ohtsu, M. Crack classification in concrete based on Acoustic Emission. Constr. Build. Mater. 2010, 24, 2339-2346. [CrossRef]

27. Wang, M.M.; Tan, C.X.; Meng, J.; Yang, B.C. Crack classification and evolution in anisotropic shale during cyclic loading tests by acoustic emission. J. Geophys. Eng. 2017, 14, 930-938. [CrossRef]

28. He, M.C.; Zhao, F.; Du, S.; Zheng, M.J. Rockburst characteristics based on experimental tests under different unloading rates. Rock Soil Mech. 2014, 35, 2737-2747.

29. Zhou, Z.L.; Wang, H.Q.; Cai, X.; Li, C. Damage evolution and failure behaviour of post-mainshock damaged rocks under aftershock effects. Energies 2019, 12, 4429. [CrossRef]

30. Niu, Y.; Zhou, X.P.; Berto, F. Evaluation of fracture mode classification in flawed red sandstone under uniaxial compression. Theor. Appl. Fract. Mech. 2020, 107, 102528. [CrossRef]

31. Zhang, Z.P.; Xie, H.P.; Zhang, R.; Zhang, Z.Z.; Gao, M.Z.; Jia, Z.Q.; Xie, J. Deformation damage and energy evolution characteristics of coal at different depths. Rock Mech. Rock Eng. 2019, 52, 1491-1503. [CrossRef]

32. Xie, H.P.; Zhou, H.W.; Liu, J.F.; Gao, F.; Zhang, R.; Xue, D.J.; Zhang, Y. Mining-induced mechanical behaviour in coal seams under different mining layouts. J. China Coal Soc. 2011, 36, 1067-1074.

33. Jia, Z.Q.; Li, C.B.; Zhang, R.; Wang, M.; Gao, M.Z.; Zhang, Z.T.; Zhang, Z.P.; Ren, L.; Xie, J. Energy evolution of coal at different depths under unloading conditions. Rock Mech. Rock Eng. 2019, 52, 4637-4649. [CrossRef]

34. Zhang, R.; Dai, F.; Gao, M.Z.; Xu, N.W.; Zhang, Z.P. Fractal analysis of Acoustic Emission during uniaxial and triaxial loading of rock. Int. J. Rock Mech. Min. Sci. 2015, 79, 241-249. [CrossRef]

35. Farhidzadeh, A.; Dehghan-Niri, E.; Salamone, S.; Luna, B. Monitoring crack propagation in reinforced concrete shear walls by Acoustic Emission. J. Struct. Eng. 2013, 139, 04013010.1-04013010.10. [CrossRef]

36. Zhang, Z.P.; Zhang, R.; Xie, H.P.; Liu, J.F.; Patrick, W. Differences in the acoustic emission characteristics of rock salt compared with granite and marble during the damage evolution process. Environ. Earth Sci. 2015, 73, 6987-6999. [CrossRef]

37. Cai, Y.B.; Wang, K.; Yuan, L.; Xu, C.; Fu, Q.; Kong, D.L. Numerical simulation and verification of unloading damage evolution characteristics of coal and rock mass during deep mining. J. China Coal Soc. 2019, 44, 1527-1535.

38. Peng, Y.; Zhang, R.; Wang, M.; Gao, M.Z.; Xu, X.L.; Li, A.Q.; Zhang, Z.Z. Application of data mining in assessing the roadway stability of mining coal rock at different depths of mines in Pingdingshan. Chin. J. Rock Mech. Eng. 2018, 37, 949-960.

39. Xie, J.; Gao, M.Z.; Zhang, R.; Li, S.W.; Tan, Q.; Jia, Z.Q. Lessons learnt from measurements of vertical pressure at a top coal mining face at Datong Tashan Mines, China. Rock Mech. Rock Eng. 2015, 49, 2977-2983. [CrossRef] 
40. Zhang, H.M.; Lei, L.N.; Yang, G.S. Damage model of rock under temperature and load. Chin. J. Rock Mech. Eng. 2014, 33, 3391-3396.

41. Peng, J.; Cai, M.; Rong, G.; Zhou, C.B.; Zhao, X.G. Stress for crack closure damage and its application to assessing stress-induced microcrack damage. Chin. J. Rock Mech. Eng. 2015, 34, 1091-1100.

42. Martin, C.D. The Strength of Massive Lac du Bonnet Granite around Underground Opening. Ph.D. Thesis, University of Manitoba, Winnipeg, MB, Canada, 1993.

43. Cai, M.; Kaiser, P.K.; Tasaka, Y. Generalized crack initiation and crack damage stress thresholds of brittle rock masses near underground excavations. Int. J. Rock Mech. Min. Sci. 2004, 41, 833-847. [CrossRef]

44. Zhao, X.G.; Cai, M.; Wang, J.; Ma, L.K. Damage stress and Acoustic Emission characteristics of the Beishan granite. Int. J. Rock Mech. Min. Sci. 2013, 64, 258-269. [CrossRef]

45. Brace, W.F.; Paulding, B.W.; Scholz, C. Dilatancy in fracture of crystalline rocks. J. Geophys. Res. 1966, 71, 3939-3953. [CrossRef]

46. Xue, L.; Qin, S.; Sun, Q.; Wang, Y.; Lee, L.M.; Li, W. A study on crack damage stress thresholds of different rock types based on uniaxial compression tests. Rock Mech. Rock Eng. 2014, 47, 1183-1195. [CrossRef]

47. Tang, Y.; Okubo, S.; Xu, J.; Peng, S.J. Study on the progressive failure characteristics of coal in uniaxial and triaxial compression conditions using 3D-digital image ccorrelation. Energies 2018, 11, 1215. [CrossRef]

(C) 2020 by the authors. Licensee MDPI, Basel, Switzerland. This article is an open access article distributed under the terms and conditions of the Creative Commons Attribution (CC BY) license (http://creativecommons.org/licenses/by/4.0/). 